\title{
Genomic characterization of Sinorhizobium meliloti AK21, a wild isolate from the Aral Sea Region
}

\author{
María Dolores Molina-Sánchez ${ }^{\dagger}$, José Antonio López-Contreras ${ }^{\dagger}$, Nicolás Toro and Manuel Fernández-López
}

\begin{abstract}
The symbiotic, nitrogen-fixing bacterium Sinorhizobium meliloti has been widely studied due to its ability to improve crop yields through direct interactions with leguminous plants. S. meliloti AK21 is a wild type strain that forms nodules on Medicago plants in saline and drought conditions in the Aral Sea Region. The aim of this work was to establish the genetic similarities and differences between S. meliloti AK21 and the reference strain S. meliloti 1021. Comparative genome hybridization with the model reference strain S. meliloti 1021 yielded 365 variable genes, grouped into 11 regions in the three main replicons in S. meliloti AK21. The most extensive regions of variability were found in the symbiotic plasmid pSymA, which also contained the largest number of orthologous and polymorphic sequences identified by suppression subtractive hybridization. This procedure identified a large number of divergent sequences and others without homology in the databases, the further investigation of which could provide new insight into the alternative metabolic pathways present in S. meliloti AK21. We identified a plasmid replication module from the repABC replicon family, together with plasmid mobilization-related genes (tra G and a VirB9-like protein), which suggest that this indigenous isolate harbors an accessory plasmid. Furthermore, the transcriptomic profiles reflected differences in gene content and regulation between S. meliloti AK21 and S. meliloti 1021 (ExpR and PhoB regulons), but provided evidence for an as yet unknown, alternative mechanism involving activation of the cbb3 terminal oxidase. Finally, phenotypic microarrays characterization revealed a greater versatility of substrate use and chemical degradation than for S. meliloti 1021.
\end{abstract}

Keywords: Comparative genome hybridization, Suppression subtractive hybridization, Sm14kOligo microarrays, Sinorhizobium meliloti, Phenotypic microarrays, Nitrogen fixation

\section{Background}

Since its discovery in 1888, the biological fixation of $\mathrm{N}_{2}$ (BFN) has been considered a potentially useful tool for land remediation (Peoples et al. 1995; Hellriegel and Wilfarth 1888). The symbiotic interaction between the soil bacterium Sinorhizobium meliloti and the leguminous plant Medicago sativa is one of the most widely studied models. S. meliloti is found in many different soil environments around the world, suggesting that this species

\footnotetext{
${ }^{*}$ Correspondence: manuel.fernandez@eez.csic.es

†María Dolores Molina-Sánchez and José Antonio López-Contreras contributed equally to this work

Grupo de Ecología Genética, Departamento de Microbiología del Suelo y Sistemas Simbióticos, Estación Experimental del Zaidín, CSIC, Calle Profesor Albareda 1, 18008 Granada, Spain
}

has broad metabolic adaptation capabilities (Souza et al. 1992; Paffetti et al. 1996; Jebara et al. 2001; Roumiantseva et al. 2002; Biondi et al. 2003; Giuntini et al. 2005; Bailly et al. 2007; Jones et al. 2007; Stiens et al. 2008; SchneikerBekel et al. 2011). Investigations of genome dynamics have been carried out at the intra- and interspecies levels in recent years in intensive studies of natural isolates of related rhizobia, discriminating between core and accessory genes (Guo et al. 2009; Galardini et al. 2011, 2013a, b; Bailly et al. 2011; Epstein et al. 2012; Sugawara et al. 2013). The complete annotated genome sequence of S. meliloti isolated from diverse soil types (agricultural fields, contaminated soils,...) and continents (1021, SM11, BL225C, AK83, GR4, Rm41) can now be obtained from databases (Galibert et al. 2001; Schneiker-Bekel

\section{黑 Springer}

(c) 2015 Molina-Sánchez et al. This article is distributed under the terms of the Creative Commons Attribution 4.0 International License (http://creativecommons.org/licenses/by/4.0/), which permits unrestricted use, distribution, and reproduction in any medium, provided you give appropriate credit to the original author(s) and the source, provide a link to the Creative Commons license, and indicate if changes were made. 
et al. 2011; Galardini et al. 2011; Martínez-Abarca et al. 2013), and several other draft genomes are also available (Galardini et al. 2013a, b).

Fixation rates in saline environments are highly dependent on the physiological state of the host plant and the salt tolerance of the rhizobia. Salt stress decreases the nodulation of leguminous plants, by inhibiting very early symbiotic events (Zahran 1991). Salinity therefore has a major impact on soil usage in agriculture. Remarkably, about $40 \%$ of soils worldwide have high salt contents and are generally considered to be unproductive. The general solution applied to overcome this problem in recent decades has been the extensive use of chemical fertilizers and salt-tolerant plants (Zahran 1999). However, the production and application of fertilizers are costly practices, both economically and ecologically. This led to efforts to isolate salt-tolerant plants and rhizobial strains mediating efficient nodulation in saline conditions, which have met with limited success (Ibragimova et al. 2006; Moawad and Beck 1991; Craig et al. 1991; Mohammad et al. 1991; Chien et al. 1992; Zou et al. 1995; El-Sheikh and Wood 1995; Lal and Khanna 1995; Mashhady et al. 1998; Hashem et al. 1998; Ohwada et al. 1998). In recent years, the emphasis has shifted to the description of genes conferring salt tolerance in free-living rhizobia and in rhizobia living in symbiosis with plants (Nogales et al. 2002; Kanesaki et al. 2002; Wei et al. 2004; Han et al. 2005; Domínguez-Ferreras et al. 2006, 2009). For instance, the trehalose biosynthesis has a role in $S$. meliloti osmotolerance and nodule occupancy (Domínguez-Ferreras et al. 2009) and noeJ, involved in LPS biosynthesis, seems to indirectly control salt tolerance in $R$. tropici (Nogales et al. 2002). S. meliloti AK21 has been isolated from nodules of Medicago sativa L. subsp. ambigua growing in the North Aral Sea Region, an area severely hit by drought, salinity and the effects of pollution (Ibragimova et al. 2006). Here, we aim to establish the main features of S. meliloti AK21 in comparison to the reference strain S. meliloti 1021. Genomic similarities were defined by comparative genome hybridization (CGH) (Salama et al. 2000; Murray et al. 2001; Malloff et al. 2001; Cummings et al. 2004; Rajashekara et al. 2004; Giuntini et al. 2005; Taboada et al. 2007; Wu et al. 2008; Guinane and Fitzgerald 2008; Carter et al. 2008), and the specific genetic differences were revealed by suppression subtractive hybridization (SSH) (Lukyanov et al. 1994; Diatchenko et al. 1996; Gurskaya et al. 1996; Akopyants et al. 1998; Galbraith et al. 2004). We also carried out transcriptional and phenotypic characterization of the natural isolate S. meliloti AK21 by microarray-based cDNA hybridization and with a phenotype microarray system (Biolog), respectively. Higher levels of sequence variability were observed in the megaplasmid pSymA than in the other replicons. Moreover, we found that S. meliloti AK21 also contained newly acquired genes, probably organized into an accessory plasmid, potentially accounting for the fitness of this wild isolate. Finally, S. meliloti AK21 displayed major differences in gene expression with respect to S. meliloti 1021, which may point toward the factors underlying nodulation efficiency in saline conditions.

\section{Results}

Comparative genomic hybridization reveals large missing regions in S. meliloti AK21 compared to S. meliloti 1021 genome

Genomic differences between the salt-tolerant strain $S$. meliloti AK21 and the reference strain S. meliloti 1021 (hereafter referred to as Rm1021) were studied by comparative genome hybridization (CGH). The sequence of the S. meliloti AK21 genome has not yet been published, albeit Eckhardt lysis analysis revealed the presence of four replicons, three large ones probably corresponding to the chromosome, pSymA and pSymB, and a $120 \mathrm{~kb}-$ length plasmid (Ibragimova et al. 2006; M. Bazzicalupo personal communication). It is known that other sequenced strains of $S$. meliloti present a genomic organization similar to Rm1021 (Galardini et al. 2011) which was annotated with 6,292 genes distributed in the three replicons: 3,429 genes in the chromosome; 1,293 genes in pSymA; and 1,570 genes in pSymB (Galibert et al. 2001). We detected 365 protein-coding genes differing between the two strains (equivalent to $5.8 \%$ of the annotated Rm1021 genome, Additional file 1), most of which were absent from or markedly different in S. meliloti AK21, with only one of these genes displaying a lower signal intensity in Rm1021 (SMa1073, 89\% identity to an ATP-binding protein). Missing regions were identified in S. meliloti AK21 which correspond to regions localized in the three major replicons of Rm1021 (Figure 1). In accordance with previous CGH analyses in S. meliloti (Giuntini et al. 2005; Stiens et al. 2008), most of the genome variations in S. meliloti AK21 (230 genes) would be located on megaplasmid pSymA (Figure 1a). By contrast, pSymB emerged as the most stable replicon, with only minor variations (29 genes; Figure 1b), consistent with the widespread view that this plasmid behaves like a true chromosome (Finan et al. 2001; Schneiker-Bekel et al. 2011; diCenzo et al. 2013; Galardini et al. 2013b). Finally, the chromosome displayed moderate variability in S. meliloti AK21, with 106 genes identified as variable (Figure 1c). All variable genes were annotated using Blast2GO and the NCBI database (Additional file 1). Genes encoding transposases were the most abundant, accounting for $23.6 \%$ of the deleted/mutated genes in $S$. meliloti AK21, followed by hypothetical/unknown genes (7.82\%), transcriptional regulator genes $(6.68 \%)$ and 


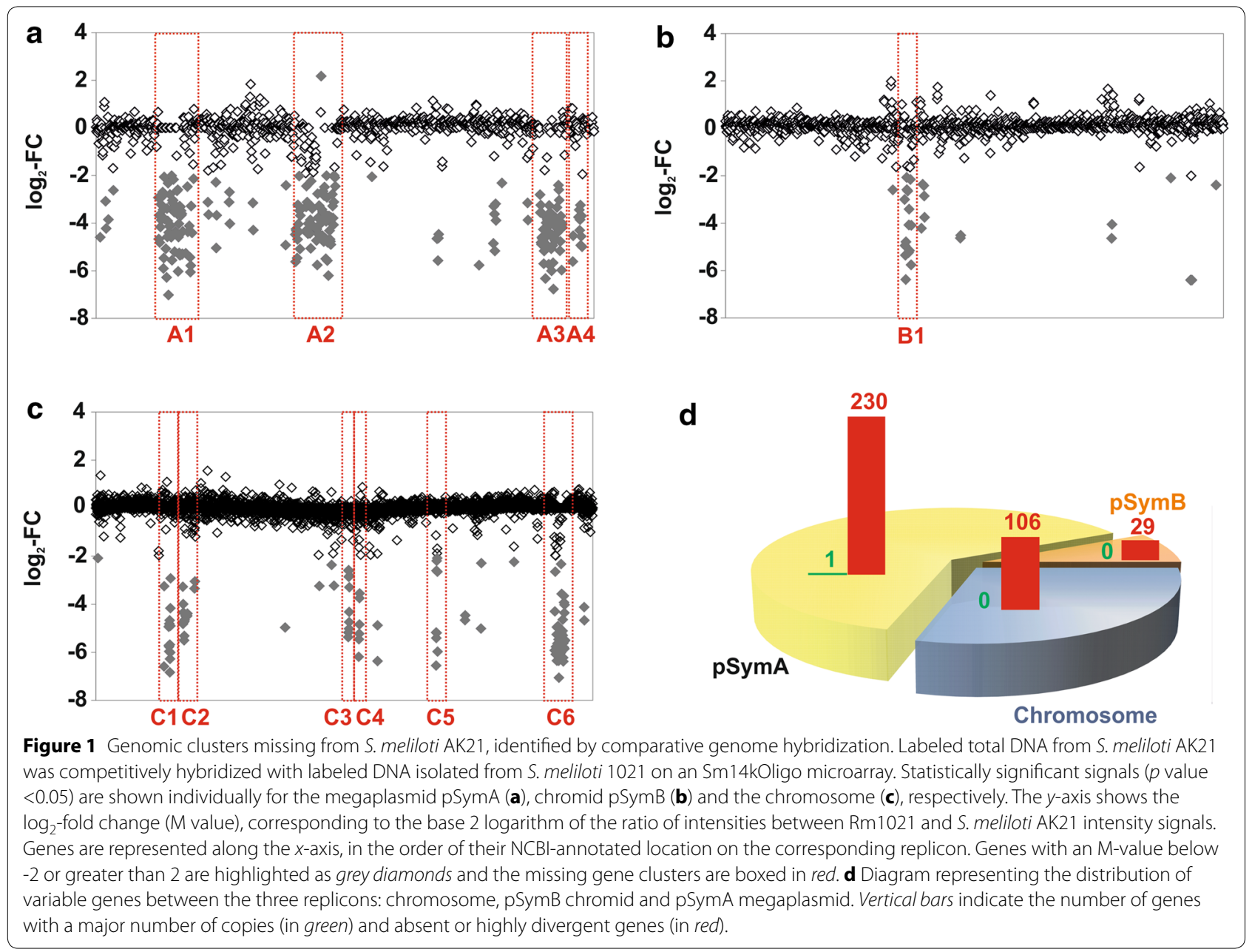

genes encoding $\mathrm{ABC}$ membrane transporters (5.45\%). As expected, the minor variable genes were related to general metabolism (3.06\%).

Further analysis of the raw data revealed that S. meliloti AK21 lacked 11 genomic clusters present in Rm1021 (Figure 1). These missing gene clusters are described in detail in Table 1. Remarkably, most of these gene clusters are flanked either by sequences with a highly complex secondary structure (generally corresponding to small RNAs) or transposase/insertion sequences (IS). Moreover, those located on the chromosome generally preceded tRNAencoding sequences. They may therefore be considered potential "hot spots" for horizontal gene transfer, due to the presence of large numbers of IS and other external origin elements (such as putative phage-encoded protein sequences). Six of these missing regions had already been identified as absent from the chromosome [I (C1); II (C2); III (C6)] and pSymA megaplasmid [II (A2); IV (A3); V (A4)] in S. meliloti SM11 (Stiens et al. 2008). The other five regions were located on the chromosome (3), the chromid pSymB (1), and the megaplasmid pSymA (1). The missing chromosome clusters corresponded to regions mostly containing genes encoding conserved hypothetical proteins and transporters, or metabolic enzymes (Table 1; Additional file 1). The B1 region encodes several proteins involved in capsular polysaccharide synthesis and transport ( $r k p \mathrm{Z} 1, r k p \mathrm{Z} 2, r k p \mathrm{R}, k p s \mathrm{~F} 2, k p s \mathrm{~T}, k p s \mathrm{M})$ and predicted calcium-binding proteins (SMb20829, SMb20838), together with several conserved hypothetical proteins (Table 1). The largest region missing from the whole of the S. meliloti AK21 genome was found in pSymA (Table 1), which has also been partially lost from S. meliloti SM11 (pSymA cluster I, $17 \mathrm{~kb}$ ). As for the losses from the chromosome, it was difficult to highlight a particular gene network, comprising metabolic genes, transporters and regulatory elements. The variation observed was probably induced by genetic exchanges mediated by mobile elements, such as insertion sequences or phages.

\section{Gene expression profile of S. meliloti AK21}

Sinorhizobium meliloti AK21 was isolated from nodules of Medicago sativa L. subsp. ambigua growing in 
Table 1 Detailed description of S. meliloti 1021 gene clusters missing from the S. meliloti AK21 genome

\begin{tabular}{|c|c|c|c|c|}
\hline Gene Clusters & Size (kb) & Gene ID ${ }^{a}$ & Number of genes & Annotated functions \\
\hline C1 & 19.6 & SMc02187-SMc02151 & 14 & Conserved hypothetical proteins; helicase DNA-binding protein \\
\hline C2 & 18.1 & SMc02326-SMc02303 & 18 & Restriction-modification system (hsdM/S/R) \\
\hline C3 & 10 & SMC00267-SMC00276 & 10 & Dehydrogenase; transketolase; transporter system; transcriptional regulator \\
\hline C4 & 7.8 & SMc00504-SMc00497 & 8 & Transcriptional regulator; putative transmembrane proteins \\
\hline C5 & 11.6 & SMC01741-SMC01554 & 13 & Conserved hypothetical proteins; acyl transferases; acyl carrier protein \\
\hline C6 & 79.1 & SMC03246-SMC03769 & 63 & Temperate phage insertion; peptide/amino-acid metabolism and transport \\
\hline A1 & 97.3 & SMa0298-SMa0476 & 94 & $\begin{array}{l}\text { Transcriptional regulator; amino acid metabolism; deshydrogenase; ABC } \\
\text { transporter systems; adenylate/guanylate cyclase (cyal2) }\end{array}$ \\
\hline A2 & 92.8 & SMa0947-SMa1141 & 107 & $\begin{array}{l}\text { ABC transporter systems; adenylate/guanylate cyclase (cyaP); regulatory } \\
\text { elements; cation transport }\end{array}$ \\
\hline A3 & 66 & SMa2113-SMa2245 & 59 & $\begin{array}{l}\text { ABC transporter systems; dehydrogenases; oxidoreductases; aminotrans- } \\
\text { ferases }\end{array}$ \\
\hline A4 & 15.4 & SMa2337-SMa2341 & 11 & Rhizobactin biosynthesis and transport \\
\hline B1 & 21.2 & SMb20823-SMb20841 & 22 & Capsular biosynthesis and export \\
\hline
\end{tabular}

a Gene identification according to the annotated genome of S. meliloti 1021.

contaminated and saline soil $(0.15 \mathrm{dS} / \mathrm{m}$, about $0.8 \%$ $\mathrm{NaCl})$. Therefore, we investigated whether differences in gene expression could contribute to the adaptation of S. meliloti AK21 to survive in these soils. We compared transcript abundances in S. meliloti AK21 grown into exponential growth phase $\left(\mathrm{OD}_{600}=0.6\right)$ in $\mathrm{TY}$ rich medium with the expression profile of Rm1021 grown in rich medium to the same growth phase by cDNA hybridization on whole-genome Sm14kOligo microarrays. Hybridization signals corresponding to the intergenic regions were not considered in this analysis. We obtained 1,446 statistically significant expression signals for Rm1021/AK21 cross-hybridization, but only 102 genes were considered to be differentially expressed $(|M| \geq 1$, see Additional file 2). In total, 47 of these genes were less strongly expressed in S. meliloti AK21 than in Rm1021, and 55 genes were more strongly expressed in $S$. meliloti AK21 (Figure 2a). The genes down-regulated in S. meliloti AK21 contained a particular high proportion of chromosomal genes (76.6\% chromosome, 17\% pSymB and $6.4 \% \mathrm{pSymA}$ ). By contrast, the up-regulated genes seemed to be much more evenly distributed between the three replicons (38.2\% chromosome, $38.2 \% \mathrm{pSymB}$ and $23.6 \% \mathrm{pSymA}$ ). From a functional perspective (Figure 2b; Additional file 2), we found that genes related to phosphate uptake were largely repressed in S. meliloti AK21 (pst $\mathrm{S}, p h o \mathrm{C}, p h o \mathrm{D}$ and $p h o \mathrm{E}$ ), as well as flagella-related genes and some other involved in chemotaxis. Moreover, we detected lower expression levels of the genes coding for the RNA polymerase sigma factor RpoE1 (SMc01418
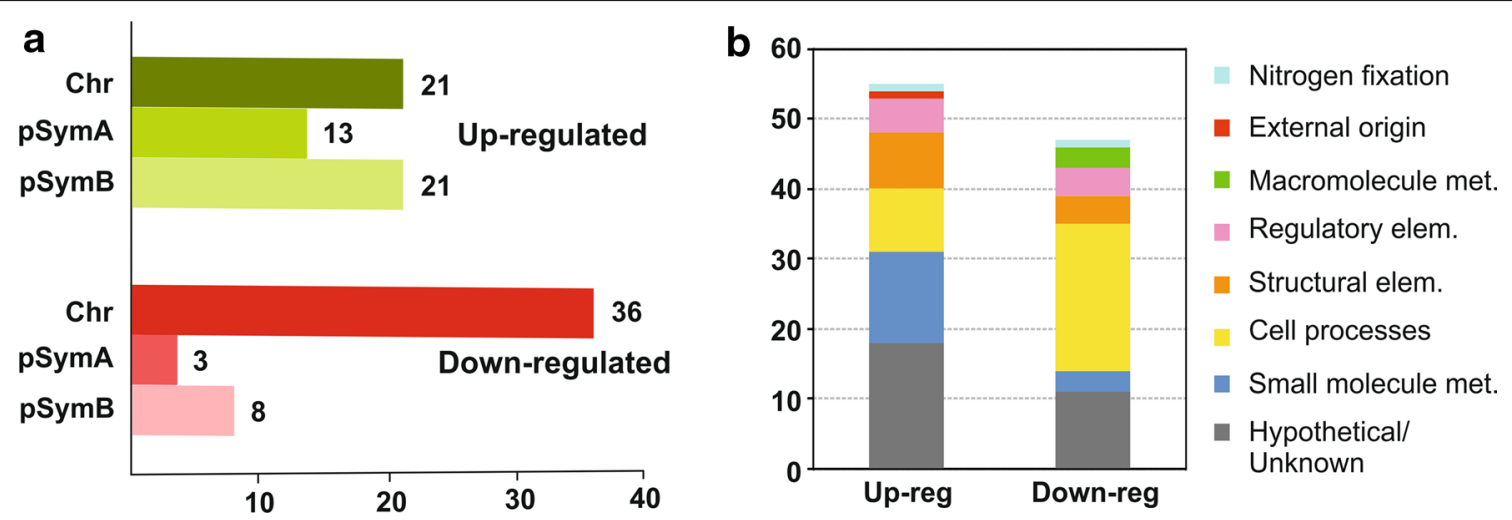

Figure $\mathbf{2}$ Distribution of genes differentially regulated in S. meliloti AK21 respect to the reference Rm1021. a Differences in color intensities are used to indicate the three replicons: chromosome (darkest), pSymA (medium intensity) and pSymB (lightest). b Functional distribution of the S. meliloti AK21 differentially expressed genes according to the KEGG and S. meliloti databases functional categories. Up-reg up-regulated genes, Down-reg down-regulated genes. 
to SMc01421). On the contrary, membrane components, including transporters and transmembrane proteins, were highly represented between the $S$. meliloti AK21 up-regulated genes. Interestingly, fix I1/P1/Q1/N1 (2.05/2.9/4.1/2.23-fold change, respectively) and fixQ2 (3.2-fold induction) exhibited increased expression in $S$. meliloti AK21 compared to Rm1021 (Additional file 2). Finally, a substantial number of hypothetical/unknown function proteins were found to be differentially regulated (29 of the 102 differentially expressed genes).

Taken together, our data point out that pSymA displayed only a few differences in gene expression despite the high level of plasticity inferred from its genetic structure. Conversely, high levels of variation were observed for the expression of genes on the chromosome.

\section{Suppression subtractive hybridization identifies different groups of genes differing with respect to the $\mathrm{Rm} 1021$ genome}

Comparative genome hybridization is a powerful tool for identifying the genes common to two genomes, such as those of Rm1021 and S. meliloti AK21, but it could not provide information about the genes present exclusively in S. meliloti AK21. We therefore carried out suppression subtractive hybridization, by the selective enrichment of DNA sequences present in our tester strain, S. meliloti AK21, but not in the reference strain, Rm1021. The 454 FLX pyrosequencing of the differential fragments from $S$. meliloti AK21 resulted in 14,588 cleared reads, most of which (98.4\%) were assembled into contigs with a mean length of $226 \mathrm{bp}$ (Figure 3a).

In total, 357 contigs were generated, ranging from 119 to $640 \mathrm{bp}$ in length. These sequences were then grouped into five categories (Figure 3b; Additional file 3): (a) false-positives displaying $100 \%$ identity to the Rm1021 genome sequence on Blastn analysis; (b) polymorphic sequences with slightly different nucleotide sequences but encoding proteins with sequences identical to those of the reference strain, as shown by Blastx analysis (100\% identity); (c) orthologous sequences, encoding proteins displaying $>85 \%$ identity to $S$. meliloti 1021 proteins on Blastx analysis; (d) divergent sequences, including those excluded from the previous categories, but for which homologous sequences were identified in the NCBI database by either Blastn or Blastx analysis; and finally, (e) orphan sequences displaying no identity to any of the known sequences in the databases. More than $25 \%$ of the sequences were false-positives, consistent with previous observations (Guo et al. 2005; Hermans et al. 2005; Zhang et al. 2005). The discriminative capacity of this technique made it possible to identify $40 \%$ of the total number of contigs as polymorphic or orthologous sequences. Most of the orthologous sequences displayed higher levels of
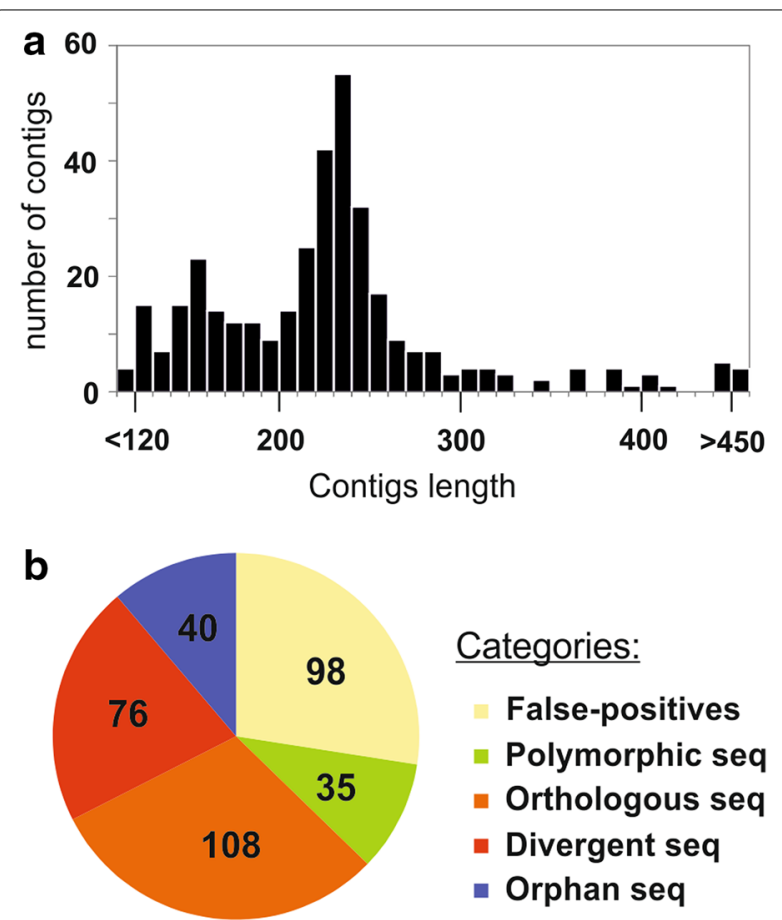

Figure 3 Characterization of suppression subtractive hybridization sequences. a Graphical representation of the number of assembled contigs ( $Y$ axis) against their length in base pairs. b Distribution of the different groups of sequences classified according to BLAST+ identification (NCBI, May, 2013). We distinguished five different categories: false-positives, which were $100 \%$ identical to sequences within the Rm1021 genome; polymorphic sequences, which had different nucleotide sequences but encoded the same protein sequence; orthologous sequences, which displayed $>85 \%$ identity to S. meliloti 1021 proteins; divergent sequences, corresponding to genes present in the databases but displaying significant identity to sequences from bacteria other than Rm1021; and orphan sequences, not found in the databases.

identity to genes identified in S. meliloti strains other than $\mathrm{Rm} 1021$, including even the related but divergent species $S$. medicae WSM419. The number of orthologous sequences (50 contigs out of 108 analysed sequences) was higher for the pSymA megaplasmid than for the chromosome (33 contigs) or pSymB (25 contigs), consistent with the differences in variability between the three replicons described above (Additional file 3). Furthermore, this relative abundance of such sequences on pSymA may account for the large number of genes related to symbiosis (noeB) and nitrogen fixation (such as $\operatorname{arcB}$, nolG and nifA) obtained in orthologous sequence identification. Verification of the flanking regions of some of the abovementioned orthologous sequences by the Southern blotting of restriction enzyme-digested total DNA revealed a similar genetic organization in the S. meliloti AK21 and Rm1021 genomes (data not shown). The orphan category 
comprised 40 of the 357 contigs, including a potentially significant number of undiscovered genes.

Finally, 76 of the 357 contigs were identified as divergent sequences, the distribution of which is shown in Figure $4 \mathrm{a}$, after grouping in identity profiles according to its presence in the bacterial strains. S. meliloti was the most frequently identified species, particularly the wild strains AK83 and BL225C. A minor group of contigs displayed identity to sequences from other symbiotic rhizobacteria, such as S. medicae, S. fredii, R. etli, Azorhizobium caulinodans and Bradyrhizobium elkanii or, even pathogenic bacteria, such as Brucella. Only five contigs displayed identity with more distantly related bacteria: Lyngbya sp. (2), Burkolderia (2) and Chelativorans sp. (1). Functional analysis of this category revealed that the vast majority of the sequences corresponded to intergenic regions (IGR) and hypothetical proteins that could not be precisely classified (Figure 4b). The other large functional group of proteins matched diverse regulatory elements, including various families of transcriptional regulators (LysR-, AraC- and GntR-like regulators), adenylate/guanylate cyclases and a sequence which could encodes an autoinducer synthesis protein with the Sec-C regulatory motif. Several phage-encoded proteins and toxin-antitoxin systems were also identified, adding to the long list already reported for S. meliloti (Bodogai et al. 2006; Sharma et al. 2008). We also found sequences displaying identity to genes involved in the biosynthesis of rhizobitoxine (RtxA), a bacterial peptide that enhances host legume nodulation by inhibiting ethylene synthesis (Sugawara et al. 2006). Furthermore, proteins putatively involved in plasmid segregation (RepA and RepB, encoded by the accessory plasmid pSmeSM11a in S. meliloti SM11; Stiens et al. 2006) and conjugative transfer (VirB9-like protein and TraG) were partially sequenced. The group of divergent sequences was completed by genes encoding putative transmembrane proteins and metabolic enzymes, such as monophenol monooxygenase, which is involved in melanin synthesis. These results provide evidence of the presence of an accessory plasmid in $S$. meliloti AK21, potentially responsible for a battery of new activities relating to some extent to nodulation efficiency

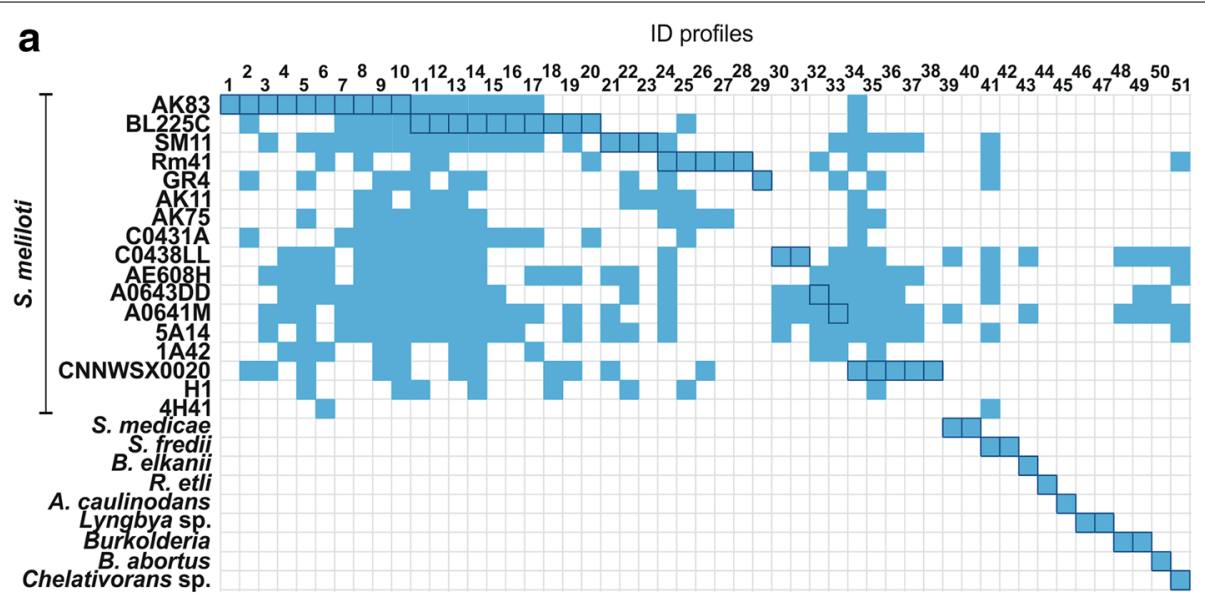

b

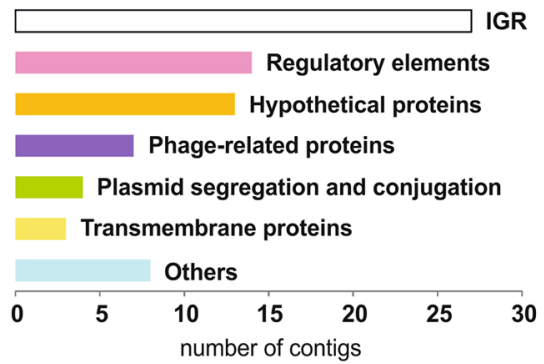

Figure 4 Analysis of the divergent sequences found by SSH. a The distribution of the divergent sequences among strains obtained in the BLAST+ analysis is shown. Identity (ID) profiles correspond to contigs which exhibit the same distribution among the different bacteria. Shaded squares indicate that the corresponding contig was totally or partially identical to a sequence present in the bacterium concerned. Highlighted squares identify the first entry in the BLAST results, corresponding to the sequence for which identity was the highest. The number of the contigs included in the different ID profiles is defined in additional file 3. b The most representative functions associated with the divergent sequences identified are plotted. 
or survival in contaminated soils. More detailed analyses of these genes would provide us with insight into the processes in which these activities are involved and their link to the phenotypic advantages observed in S. meliloti AK21.

\section{Phenotypic microarrays identify interesting metabolic pathways in S. meliloti AK21}

We compared the metabolic capabilities of $S$. meliloti AK21 with those of the reference strain Rm1021, with a phenotypic microarray (PM, Bochner et al. 2001). We measured the effects on bacterial respiration rates of adding various sources of carbon (PM1, PM2), nitrogen (PM3, PM6, PM7, PM8), phosphorus and sulfur (PM4) to the culture medium. We also investigated nutrient stimulation (PM5), osmotic and $\mathrm{pH}$ tolerance in terms of growth (PM9, PM10) and chemical sensitivity (PM1120). In total, we studied 947 different growth conditions and determined resistance to different concentrations of
240 chemical reagents, including antibiotics, xenobiotics, fungicides and contaminants. We observed differences in growth rate between the strains in 28 of the 1,907 assayed conditions, corresponding to metabolic advantages of $S$. meliloti AK21 over Rm1021 (Table 2; Additional file 4). When 2-deoxy-D-ribose was added as a sole carbon source, S. meliloti AK21 grew better than Rm1021. Therefore with the exception of the use of 2-deoxy-D-ribose, the carbon use pathways of the two strains are similar. Strikingly, enhanced respiration rates were observed when most cyclic nucleoside monophosphates (cUMP, cCMP and cGMP) and some nucleoside monophosphates (CMP and UMP) were used as the phosphorous source. Sulfur phenotypes were also gained, with growth being sustained by L-methionine sulfoxide, methane sulfonic acid, $N$-acetyl-D,L-methionine, L-cysteic acid and cysteamine as the sole source of this non-metallic element. In general, S. meliloti AK21 seemed to make better use of diverse sources of $\mathrm{P}$ and $\mathrm{S}$ for growth than did

Table 2 Metabolic capabilities acquired by S. meliloti AK21, as identified on phenotypic microarrays

\begin{tabular}{|c|c|c|}
\hline Tested compound & Average height $^{\mathrm{a}}$ & Metabolic process \\
\hline 2-Deoxy-D-ribose & 41 & C-Source, carbohydrate \\
\hline Leu-Leu & 61 & N-Source, peptide \\
\hline Val-Tyr-Val & 51 & N-Source, peptide \\
\hline Gly-Asn & 43 & N-Source, peptide \\
\hline Lys-Asp & 43 & N-Source, peptide \\
\hline Val-Phe & 40 & N-Source, peptide \\
\hline Uridine $2^{\prime}, 3^{\prime}$-cyclic monophosphate & 53 & P-Source, organic \\
\hline Cytidine $2^{\prime}, 3^{\prime}$-cyclic monophosphate & 46 & P-Source, organic \\
\hline Guanosine $2^{\prime}, 3^{\prime}$-cyclic monophosphate & 43 & P-Source, organic \\
\hline Cytidine $3^{\prime}$-monophosphate & 41 & P-Source, organic \\
\hline Uridine $3^{\prime}$-monophosphate & 40 & P-Source, organic \\
\hline L-methionine sulfoxide & 52 & S-Source, organic \\
\hline Methane sulfonic acid & 52 & S-Source, organic \\
\hline N-Acetyl-D,L-Methionine & 45 & S-Source, organic \\
\hline L-Cysteic acid & 44 & S-Source, organic \\
\hline Cysteamine & 42 & S-Source, organic \\
\hline $5 \%$ potassium chloride & 61 & Osmotic sensitivity, $\mathrm{KCl}$ \\
\hline $\mathrm{pH} 10$ & 59 & $\mathrm{pH}$, growth at 10 \\
\hline $\mathrm{X}-\mathrm{PO} 4$ & 51 & Aryl phosphatase \\
\hline Benserazide & 96 & aa metabolism, aromatic amino acid decarboxylase inhibitor \\
\hline Tylosin & 55 & Protein synthesis, 50 S ribosomal subunit, macrolide \\
\hline Rifampicin & 126 & RNA polymerase \\
\hline Pipemidic acid & 106 & DNA topoisomerase \\
\hline Lomefloxacin & 72 & DNA topoisomerase \\
\hline Sodium orthovanadate & 78 & Toxic anion, $\mathrm{PO}_{4}$ analog \\
\hline Lawsone & 93 & Oxidizing agent \\
\hline Domiphen bromide & 76 & Membrane, detergent, cationic, fungicide \\
\hline Tolylfluanid & 193 & Fungicide, phenylsulfamide \\
\hline
\end{tabular}

a Average height is the area under the curve divided by number of measurements. 
other S. meliloti strains. However, it metabolized cysteine derivatives and methane sulfonic acid less efficiently (Biondi et al. 2009). It also displayed higher respiration rates in the presence of some oligopeptides: leu-leu, glyasn, lys-asp, val-phe and val-tyr-val. S. meliloti AK21 grew at $\mathrm{pH} 10$ and in the presence of $5 \%$ potassium chloride, unlike other $S$. meliloti isolates (Biondi et al. 2009). Several drugs were identified as growth-enhancing compounds, affecting nucleic acid metabolism (pipemidic acid, lomefloxacin and rifampicin), amino acid metabolism (benserazide and tylosin), phosphate metabolism (X- $\mathrm{PO}_{4}$ and sodium orthovanadate), and pesticide tolerance (tolylfluanid, domiphen bromide and lawsone). The tolerance of S. meliloti AK21, in terms of growth, may therefore reflect the adaptation of this strain to an adverse environment, containing high levels of fertilizer, salt and other chemical contaminants.

\section{Discussion}

Sinorhizobium meliloti AK21 was isolated from a highly polluted and salinized, dry soil in the northern Aral Sea Region. We compared the genomes of S. meliloti AK21 and the sequenced strain S. meliloti 1021, and analysed differential gene expression and carried out phenotypic characterization. We found that 364 out of 365 differing genes of S. meliloti 1021 were missing from S. meliloti $\mathrm{AK} 21$, and that these genes were mainly clustered in 11 regions of variable length, generally flanked by mobile elements and also by conserved sequences with a complex secondary structure. Genetic variations were most frequently found to genes located on the megaplasmid pSymA of Rm1021, followed by the chromosome and pSymB. We also detected a set of genes in S. meliloti AK21 that were polymorphic or orthologous to genes in other rhizobia, and divergent sequences that were present in more phylogenetically distant bacteria. The gene expression profile revealed differences in regulation between free-living S. meliloti AK21 and Rm1021, with a greater number of genes up-regulated than down-regulated relative to Rm1021. Finally, S. meliloti AK21 grew in various limiting conditions, although the genes involved in these new capabilities have yet to be determined.

Rhizobial genomes are usually partitioned in several replicons, the number of which depends on the species; though additional, small replicons could be present in different isolates. The chromosome and the pSymB chromid display almost perfect correlation for the presence of genes, with only a few inserted, deleted or rearranged regions (Galardini et al. 2011). However, the symbiotic megaplasmid pSymA, and the accessory plasmids described in rhizobia, have a higher frequency of genomic rearrangements, making them dynamic structures prone to genome evolution and adaptation
(Mavingui et al. 2002; Giuntini et al. 2005; Stiens et al. 2006; Galardini et al. 2011, 2013b; Bailly et al. 2011). Our comparative genomic hybridization and suppressive subtraction hybridization data support these previous findings, because the longest regions lost and the highest proportion of polymorphic and orthologous genes mapped to pSymA of Rm1021. The proportion of variable genes in the whole genome of $S$. meliloti AK21 was about $5.8 \%$, similar to the results reported for previous studies of other S. meliloti strains (Giuntini et al. 2005; Stiens et al. 2008). However, most of this variability (3.6\%) was associated with $\mathrm{pSymA}$, followed by the chromosome (1.7\%) and pSymB (0.5\%). An in silico analysis comparing our $\mathrm{CGH}$ results and the whole-genome data for a collection of recently sequenced $S$. meliloti strains revealed that most of the gene clusters missing from the genome had also been lost from these other strains, suggesting that these regions were potentially acquired by $\mathrm{Rm} 1021$, rather than lost from S. meliloti AK21 (see Additional file 5). We found that almost $20 \%$ of the pSymA genes were missing from $S$. meliloti AK21 or differed substantially from those found in Rm1021. In addition, insertion sequences and transposons have frequently been found on pSymA-type plasmids (Barloy-Hubler et al. 2000; Barnett et al. 2001; Galibert et al. 2001; Schneiker-Bekel et al. 2011). Thus, these plasmids would be expected to display higher rates of rearrangement, due to the activity of these mobile elements. Indeed, the rhizobial symbiotic clusters, generally linked to pSymA, is generally thought to have been acquired by horizontal transfer between different species, and even genera, because nif-nod regions are surrounded by transposases and repeated sequences (Sullivan and Ronson 1998; Mavingui et al. 2002; Young et al. 2006; Crossman et al. 2008; Galardini et al. 2011; Bailly et al. 2011; Epstein et al. 2012). Most transposaseencoding genes are found in regions carrying traces of genomic rearrangements (Galardini et al. 2011). The core genome is generally considered to define bacterial phylogeny, whereas the accessory genes shed light on biological aspects of the symbiosis (Young et al. 2006; Galardini et al. 2011, 2013b; Bailly et al. 2011; Epstein et al. 2012; Tian et al. 2012; Sugawara et al. 2013). Our results are consistent with this hypothesis, because the divergent sequences obtained by SSH mostly matched with $S$. meliloti, mainly with $S$. meliloti AK83, which was isolated from the same ecological niche as S. meliloti AK21.

The major differences in gene expression between Rm1021 and S. meliloti AK21 concerned membrane components. Flagellum genes were much less strongly expressed in S. meliloti AK21 than in Rm1021. In addition, previous studies on $S$. meliloti 1021 reported the down-regulation of a number of genes involved in chemotaxis and cell motility after an osmotic upshift or 
during osmoadaptation (Rüberg et al. 2003; DomínguezFerreras et al. 2006). Flagella are usually linked to cell motility, unless flagellum-independent bacterial movement has also been described (Nogales et al. 2012), and the correct regulation of flagellum movement is essential for legume nodulation (Soto et al. 2002). In S. meliloti, surface motility is regulated by ExpR, in conjunction with the Sin-AHLs quorum-sensing system, in different manners, depending on cell density (Hoang et al. 2008; Nogales et al. 2012). At high population densities, both regulatory systems inhibit the flagellar regulon through the visNR transcriptional regulator. S. meliloti AK21 is an ExpR-proficient bacterium producing large amounts of capsular polysaccharide, whereas Rm1021 is a nonmucoid strain in which an insertion sequence interrupts the coding sequence of $\operatorname{expR}$ (Pellock et al. 2002). We obtained indirect evidence for the production of flagella in S. meliloti AK21, which displayed swimming motility, which is strictly dependent on flagella (data not shown). Consistent with this finding, S. meliloti AK21 does not probably swarm in semisolid agar plates, instead moving over the surface by sliding (data not shown). Rhizobactin 1021 is a siderophore that is thought to be required for surface mobility in Rm1021 (Nogales et al. 2010, 2012). According to our CGH data, S. meliloti AK21 seems to lack the rhizobactin biosynthesis operon, suggesting that this sliding motility is probably rhizobactin-independent. However, more detailed studies of flagellum production and surface motility are required to obtain insight into these two processes in S. meliloti AK21. Furthermore, the determination of $S$. meliloti genome expression profiles led to the identification of a set of ExpR-controlled genes involved in other important cellular processes, such as nitrogen fixation, metabolism and metal transport (Hoang et al. 2004). As we compared an ExpR-deficient strain (Rm1021) and S. meliloti AK21, a strain that can potentially produce this regulatory protein, it is not surprising that a detailed analysis of our data revealed several genes previously reported to belong to the ExpR/ Sin operon. Similarly, we also identified several genes related to the PhoB regulatory network, which was found to be downregulated in the S. meliloti AK21 transcriptomic dataset (19 of 102 differentially expressed genes). PhoRB is a two-component regulatory system involved in diverse cellular processes, such as exopolysaccharide biosynthesis, de novo NAD biosynthesis, biofilm formation and secondary metabolite production, but its most frequently studied functions in S. meliloti relate mostly to phosphate metabolism and starvation (Krol and Becker 2004; Yuan et al. 2006). However, these authors reported differential regulation of this two-component system in Rm1021 and Rm2011, and concluded that Rm1021 displayed moderate levels of $\mathrm{PhoB}$ activation, even in the presence of sufficient phosphate, due to a deletion in the $p s t C$ gene from $R m 1021$. Therefore it is possible that much of the differential expression observed between $S$. meliloti AK21 and Rm1021 is due to PhoB-dependent regulation. In summary, since there seems to be an ExpR and PhoB differential regulation between Rm1021 and S. meliloti AK21, we have to be cautious to interpret the microarrays expression data.

Finally, FixQ1 and FixQ2 were found to be induced in $S$. meliloti AK21 grown in standard conditions, that is to say rich medium and aerobiosis. The $f i x \mathrm{NOQP}$ genes encode the membrane complex cytochrome $c b b 3$ oxidase, a final electron acceptor in the respiratory chain, which has a high affinity for $\mathrm{O}_{2}$ under the low oxygen concentrations found in most rhizobia (i.e. in symbiosis with plants) (Becker et al. 2004; Torres et al. 2013). FixQ seems to be a structural element that stabilizes the interaction of CcoP with the CcoNO core complex (Peters et al. 2008). The FixLJ/FixK regulatory proteins control the expression of $S$. meliloti genes required for nitrogen fixation and for microaerobic respiration within nodules, including the fixNOQP1 and two operons strongly induced under low-oxygen conditions in free-living bacteria and in bacteroids, respectively (Bobik et al. 2006). The fix 1 , $f i x \mathrm{~N} 2, f i x \mathrm{I}$ and $f i x \mathrm{P}$ genes were also identified as induced, but to a much lesser extent than $f i x \mathrm{Q}$. We observed a slight repression of $f(x)$, fix $\mathrm{K} 1$ and $f i x \mathrm{~K} 2$, whereas other genes from the FixLJ/FixK regulon were found to be differentially regulated (induced or repressed, depending on the gene). These data suggest that fixNOQP could be constitutively expressed in S. meliloti AK21 and could be related to the stress response, whereas in Rm1021 is under the tight control of FixL/FixK. The induction of cytochrome $c b b 3$ may increase the ATP content of the bacterium in preparation for the establishment of symbiosis, considering the key role of fixNOQP1 in early stages of association with plants (Torres et al. 2013). This protein complex may therefore play a role in the adaptation of $S$. meliloti for nodulation in saline conditions. These results suggest an alternative pathway for the activation of the fix genes in response to the presence of salt and/or other chemical compounds in the environment.

In terms of phenotypic adaptations, we observed that S. meliloti AK21 is able to efficiently support growing in a wide variety of $\mathrm{S}, \mathrm{N}$ and $\mathrm{P}$ sources as well as in contaminated environments. Similar studies carried out with bacteria isolated from the same region, S. meliloti AK83 or AK58, revealed that these natural isolates, mainly AK58, are able to proliferate in different $\mathrm{C}$ and $\mathrm{N}$ sources and in a plethora of antibiotics and other chemicals (Biondi et al. 2009; Galardini et al. 2014). However, these phenotypes are not shared with $S$. meliloti AK21. It is likely that each organism could acquire particular abilities for 
surviving in hostile environments. Conversely, Rm1021 has been grown in laboratory conditions for a long period and does not require these metabolic adaptations.

ARDRA analysis and 16S rRNA gene sequencing classified AK21 as S. meliloti. Eckhardt lysis analysis of plasmid content revealed the presence of three major replicons, probably corresponding to the chromosome, pSymA and $\mathrm{pSymB}$, and a cryptic plasmid of about $120 \mathrm{~kb}$ in size (Ibragimova et al. 2006; M. Bazzicalupo personal communication). Our SSH data are consistent with this experimental evidence, because we found proteins involved in plasmid replication/partitioning from the rep ABC family to be exclusive to S. meliloti AK21. Moreover, we identified several genes usually carried by accessory plasmids, including a putative mobilization module TraG/Vir (pSmeSM11a) and a monophenol monooxygenase gene (pRmeGR4b). These accessory plasmids carry genes that could confer an adaptive advantage on the host bacterium and they are widespread and interchangeable between natural rhizobial populations (more than $50 \%$ of rhizobia harbor at least one cryptic plasmid; Mercado-Blanco and Toro 1996; Stiens et al. 2006; Galardini et al. 2013b). Thus, the rhizobitoxine biosynthesis operon identified in S. meliloti AK21 may be present on the accessory plasmid. This phytotoxin was first described in Bradyrhizobium species as being associated with leaf chlorosis in susceptible host plants (Ruan and Peters 1992; Ruan et al. 1993). It is also produced by other pathogenic microorganisms, such as Pseudomonas and Agrobacterium, and has recently been found in a group of S. medicae isolates (Bailly et al. 2011). Rhizobitoxine interferes with ethylene synthesis in plant tissues, by inhibiting the ACC synthase (Yuhashi et al. 2000; Sugawara et al. 2006). Likewise, the $a c d S$ gene has been shown to be present on pSmeSM11a, one of the accessory plasmids of S. meliloti SM11 (Stiens et al. 2006). It encodes an ACC deaminase that metabolizes the precursor of the phytohormone ethylene, thereby enhancing nodulation (Ma et al. 2004). Similar strategies for the improvement of nodulation, through the inhibition of ethylene biosynthesis, could thus be mediated by accessory genes, conferring fitness advantages for the symbiotic interaction. The presence of these genes on transmissible plasmids would facilitate spread within the population of bacteria in the soil.

\section{Conclusions}

Rhizobiaceae is a family of bacteria of enormous agricultural importance, due to their ability to fix atmospheric nitrogen in symbiosis with leguminous plants (Jones et al. 2007). They occur naturally in most agricultural soils, but fluctuations in environmental conditions, such as temperature, osmolarity, $\mathrm{pH}$ or nutrient availability, severely affect their symbiotic capacity (Zahran 1999; Rüberg et al. 2003). For this reason, studies of the mechanisms by which indigenous populations of rhizobia adapt to unbalanced environments are required. $S$. meliloti AK21 was isolated from highly degraded and saline soils in the Aral Sea Region, in which it efficiently nodulates $M$. sativa. In this study, we demonstrated the existence of genetic, transcriptomic and phenotypic differences between this wild strain and the laboratory reference strain, S. meliloti 1021. The chromosome of $S$. meliloti AK21 had lost six regions, but only minor differences in gene expression were observed. Similarly, the symbiotic plasmid pSymA lacked four regions, and three of these deletions were extensive. However, the largest differences in gene expression were found for this replicon. Conversely, the chromid pSymB lacked only one short region. A significant number of these deleted gene clusters were flanked by transposable and repeated elements that could potentially be involved in homologous recombination. We also identified several sequences that were absent from S. meliloti 1021 but present in other rhizobia, and sequences present exclusively in S. meliloti AK21. These groups of divergent and orphan contigs may account for the phenotypic advantages of the wild isolate over the reference strain. Moreover, we detected several proteins involved in plasmid conjugation and segregation, and several genes also reported to be present on accessory plasmids in other S. meliloti strains. Then, we obtained genetic evidence for the presence of an accessory plasmid in S. meliloti AK21. Finally, we discovered a large set of genes differentially expressed between S. meliloti AK21 and Rm1021. Membrane components predominated over all other cellular functions, but we detected two proteins related to nitrogen fixation, FixQ1 and FixQ2. These proteins form part of the $c b b 3$ electron transport system and may be involved in enhancing the nodulation behaviour of rhizobia in saline conditions.

\section{Methods}

\section{Bacterial strains and culture conditions}

Sinorhizobium meliloti 1021 (Rm1021) forms nitrogenfixing nodules in Medicago hosts. This streptomycinresistant derivative of S. meliloti SU47 has been grown under laboratory conditions for 38 years (Meade and Signer 1977). Rm1021 was the first S. meliloti strain to be sequenced and is therefore considered to be the reference strain for this species. S. meliloti AK21 was isolated from nodules of Medicago sativa L. subsp. ambigua (formerly named M. trautvetteri) growing in Kazakhstan, in the northern Aral Sea Region (State Research Center of the Russian Federation Collection in St. Petersburg; Ibragimova et al. 2006). Rhizobia were cultured at $28^{\circ} \mathrm{C}$ 
in rich TY broth $(5 \mathrm{~g} / 1$ tryptone, $3 \mathrm{~g} / \mathrm{l}$ yeast extract, $0.9 \mathrm{~g} / \mathrm{l}$ $\mathrm{CaCl}_{2}$ ), with constant shaking at $180 \mathrm{rpm}$.

\section{Isolation of S. meliloti genomic DNA}

DNA was extracted with the RealPure genomic DNA extraction Kit (Durviz, S.L.U., Valencia, Spain), according to a modified version of the procedure recommended by the manufacturer. Briefly, pelleted cells were washed with $0.1 \%$ L-laurylsarcosine in TE buffer, $\mathrm{pH} 8$. The cells were lysed by incubation for $5 \mathrm{~min}$ at $80^{\circ} \mathrm{C}$ and then subjected to RNAse treatment at $37^{\circ} \mathrm{C}$ for $60 \mathrm{~min}$. RNA and proteins were removed, and the DNA was precipitated with 2-propanol. Purified DNA was quantified spectrophotometrically (Nanodrop, PeqLab, Erlangen, Germany). Highly pure genomic DNA ( $A 260 / A 280$ ratio of 1.8-2.0) was obtained at a final concentration of about $1.2-1.4 \mu \mathrm{g} / \mu \mathrm{l}$.

\section{Total RNA extraction from S. meliloti}

High-quality total RNA was isolated with the RNeasy Mini Kit (Qiagen, Barcelona, Spain), according to a modified version of the manufacturer's protocol. We harvested six $\mathrm{OD}_{600}$ units of bacterial cultures in the exponential growth phase by rapid centrifugation and froze them in liquid nitrogen. The samples were then thawed on ice, and the cells were resuspended in $100 \mu \mathrm{l}$ of freshly prepared lysozyme solution $(0.4 \mathrm{mg} / \mathrm{ml})$ and the samples were incubated at room temperature for $5 \mathrm{~min}$. The bacteria were then disrupted by adding $350 \mu \mathrm{l}$ of RLT buffer and shaking vigorously, and the disrupted cells were then centrifuged for $2 \mathrm{~min}$. The cleared lysates were mixed with $250 \mu \mathrm{l}$ of $100 \%$ ethanol, transferred to the supplied spin columns and centrifuged. The columns were then washed according to the manufacturer's instructions and the RNA was eluted in $120 \mu \mathrm{l}$ of water. All trace DNA contamination was removed by DNA digestion with 30 units of RNAse-free DNAse I (Qiagen, Barcelona, Spain) at $28^{\circ} \mathrm{C}$ for $90 \mathrm{~min}$. We then added $490 \mu \mathrm{l}$ of RLT buffer and $350 \mu \mathrm{l}$ of $100 \%$ ethanol to the samples and the mixture was layered onto a new column. The RNA was eluted in $50 \mu \mathrm{l}$ MilliQ water, and further purified and concentrated on Microcon 30 columns (Millipore Iberica S.A.U., Madrid, Spain). RNA concentration was measured with a Nanodrop spectrophotometer and RNA quality was checked by gel electrophoresis.

\section{Comparative genome hybridization and data analysis}

For genomic comparisons, we used whole-genome Sm14kOligo microarrays supplied by the Center for Biotechnology, University of Bielefeld, Germany. These microarrays carry 50-mer to 70-mer oligonucleotide probes directed against coding regions and intergenic regions (see http://www.cebitec.uni-bielefeld. de/transcriptomics/transcriptomics-facility/sm14koli. $\mathrm{html}$ for further details). Competitive hybridization was carried out twice for each restriction enzyme and strain, with dye swapping between the test and reference strains. Total DNA was labeled with the Bioprime Total Genomics Labeling System (Invitrogen, Madrid, Spain), as previously described by Giuntini et al. (2005). In brief, we labeled $10 \mu \mathrm{g}$ of RsaI- or TaqAI-digested genomic DNA with dCTP coupled to Alexa Fluor 3 or Alexa Fluor 5 in a $50 \mu \mathrm{l}$ reaction mixture containing random primers and the Klenow fragment of DNA polymerase I, by incubation at $37^{\circ} \mathrm{C}$ for $2 \mathrm{~h}$. The unincorporated fluorescent nucleotides were removed and the samples were combined as appropriate and mixed with $30 \mu \mathrm{l} \mathrm{Cot}-1$ DNA $(1 \mathrm{mg} / \mathrm{ml}), 17 \mu \mathrm{l}$ yeast t-RNA $(6 \mathrm{mg} /$ $\mathrm{ml}$ ) and $450 \mu \mathrm{l}$ TE buffer. Microcon 30 filter columns (Millipore Iberica S.A.U., Madrid, Spain) were used to concentrate the probes down to a final volume of about $35 \mu \mathrm{l}$. Each combined sample was mixed with $8.5 \mu \mathrm{l}$ of $20 \times$ SSC and $0.74 \mu \mathrm{l}$ of 10 SDS and denatured by heating at $100^{\circ} \mathrm{C}$ for $1.5 \mathrm{~min}$. The sample was then incubated at $37^{\circ} \mathrm{C}$ for $30 \mathrm{~min}$ and the hybridization probe was added to the pretreated microarray under a coverslip. Hybridization was performed at $65^{\circ} \mathrm{C}$ for $16 \mathrm{~h}$, within a chamber in a water bath. The coverslip was removed by vigorous shaking in $2 \times \mathrm{SSC} / 0.2 \% \mathrm{SDS}$ at $65^{\circ} \mathrm{C}$ for $30 \mathrm{~s}$ and slides were washed successively with: $2 \times \mathrm{SSC} / 0.2 \% \mathrm{SDS}$ at $65^{\circ} \mathrm{C}$ for $5 \mathrm{~min}, 0.2 \times \mathrm{SSC} / 0.1 \%$ SDS at $65^{\circ} \mathrm{C}$ for $2 \mathrm{~min}$ and then twice with $0.2 \times$ SSC at room temperature, for $2 \mathrm{~min}$ each. The slides were immediately dried by centrifugation and the data were acquired on a GenePix 4000A scanner (Axon Instruments). Mean signal intensities for each spot were quantified with GenePix Pro 5.1 (Axon Instruments, Union City, CA, USA).

Raw data were normalized with MADE-4-2C (Fernandez-Pozo 2012), applying the LOESS scaled algorithm. Further statistical analysis of the normalized data using the same software allowed determining the differential presence of genes. A gene was considered to display a significant difference in hybridization if the intensity of the spot was outside the values included in the $95 \%$ confidence interval ( $t$ test, $p$ value $<0.05$, corrected for multiple testing) and the absolute value for the $\log _{2}$-ratio of intensities was higher than 2 . We obtained signal for 13,618 spots of the total 29,952 (total number of features). A positive $\log _{2}$-fold-change means that hybridization intensity was greater for S. meliloti AK21 than for $R m 1021$, indicating gene duplication. A negative $\log _{2}-$ ratio of intensities indicated higher signal intensity for Rm1021, consistent with the corresponding gene being highly divergent in or missing from the $S$. meliloti AK21 genome. 
Microarray hybridization and statistical analysis of the data We analysed the expression of the genes common to Rm1021 and S. meliloti AK21 by competitive cDNA hybridization on Sm14kOligo microarrays. The procedure was basically as previously described (Rüberg et al. 2003). In brief, $15 \mu \mathrm{g}$ of total RNA was reverse-transcribed with $15 \mu \mathrm{g}$ of random hexamer oligonucleotides, 400 U SuperScript II reverse transcriptase (Invitrogen, Madrid, Spain) and a $100 \mathrm{mM} \mathrm{dNTP} \mathrm{+} \mathrm{aa-dUTP} \mathrm{mixture}$ (dNTPs: Roche Diagnostics, Barcelona, Spain; aa-dUTP: Sigma-Aldrich Quimica SL, Madrid, Spain) at $42^{\circ} \mathrm{C}$ for $2 \mathrm{~h}$. After alkaline hydrolysis of the RNA, amino-allyl modified first strand cDNAs was cleaned using CyScribe GFX Purification Kit (GE Healthcare, Seville, Spain) and coupled with Cy3- and/or Cy5-NHS ester dyes (GE Healthcare, Seville, Spain) by incubation at room temperature for 2-3 $\mathrm{h}$. The cDNA generated from Rm1021 RNA was labeled with $\mathrm{Cy} 5$ fluorescent dye, whereas the test cDNA from S. meliloti AK21 was coupled with the Cy3 fluorophore. Samples with different labels were mixed and the uncoupled dyes were removed with the CyScribe GFX Purification Kit (GE Healthcare, Seville, Spain). The dried probe was diluted in $45 \mu$ l DIG Easy Hyb solution (Roche Diagnostics, Barcelona, Spain) supplemented with $5 \mu \mathrm{g}$ salmon sperm DNA. The denatured probe solution was poured onto the microarrays after the prehybridization step. Then, the microarrays were covered with cover slips and incubated in a hybridization chamber in a water bath at $42^{\circ} \mathrm{C}$ for at least $16 \mathrm{~h}$. Microarrays were then washed at room temperature, as described above.

Data acquisition and processing are described in the section dealing with CGH. We analyse three biological and two technical replicates, swapping the dyes between the test and reference strains. Differentially expressed genes were identified on the basis of the following criteria: $p$ value $<0.05$ ( $t$ statistics) and $\log 2$-ratio of intensities $\geq 1$ or $\leq-1$. A positive value corresponds to genes more strongly expressed in S. meliloti AK21 than in Rm1021. Conversely, a negative ratio indicates that the corresponding genes are repressed or less expressed in $S$. meliloti AK21.

\section{Suppression subtractive hybridization and data processing} The PCR-Select Bacterial Genome Subtraction kit (Clontech, Madrid, Spain) was adapted for the detection of genes present in $S$. meliloti AK21, as the tester strain, but not in the driver strain S. meliloti 1021. We digested $2 \mu \mathrm{g}$ each of the driver and tester genomic DNAs separately with RsaI, to obtain short, blunt-ended fragments. The enzyme was removed and the digested tester DNA sample was split into two batches, each of which was ligated with a different, partially complementary adaptor supplied by the manufacturer, in the kit. These adaptors could bind to only one of the ends of the DNA fragments. Two successive hybridizations were then carried out to enrich the sample in tester-specific molecules absent from the reference genome. The adaptor-bound tester DNA and the RsaI-digested driver DNA were denatured by heating at $98^{\circ} \mathrm{C}$ for $2 \mathrm{~min}$, mixed in a $1: 50$ (tester/driver) ratio and renatured by heating at $64^{\circ} \mathrm{C}$ for $90 \mathrm{~min}$. In a second hybridization step, the two previously annealed mixtures were combined and mixed with $300 \mathrm{ng}$ of new freshly denatured driver genomic DNA. The reaction mixture was incubated at $64^{\circ} \mathrm{C}$ for $16 \mathrm{~h}$. Two successive nested PCRs increased the enrichment of the sample in molecules flanked by a different adaptor. The second PCR products were sent for DNA pyrosequencing by 454 FLX method (Roche) at LifeSequencing SL (Valencia, Spain).

SeqTrim software was used to clean sequences and to remove adaptor sequences and PCR artifacts (Falgueras et al. 2010). The resulting sequences were assembled into contigs by CAP3 (Huang and Madan 1999). Two sequences were considered to constitute a single contig when they overlapped by at least $20 \mathrm{nt}$ and overall identity exceeded 95\%. Finally, BLAST +2.2 .25 (Blastn and Blastx) was used for sequence comparison and identification (Camacho et al. 2009). Blast2GO was used for the annotation of highly divergent sequences (Conesa et al. 2005) and orthologs were identified by the BBH method (Altenhoff and Dessimoz 2009). These sequences were uploaded as a library into the GSS database [LIBGSS: 038882].

\section{Phenotypic microarray analysis}

Sinorhizobium meliloti AK21 and Rm1021 were assayed on phenotypic microplates (BiOLOG, Hayward, CA, USA) testing hundreds of different conditions. Runs were performed for the first twenty 96-well microplates available. Bacterial growth was measured in the presence of different $\mathrm{C}, \mathrm{P}, \mathrm{N}$ and $\mathrm{S}$ sources, fungicides and xenobiotic compounds, together with antibiotic resistance. Survival was also analysed in the presence of osmolytes and at different $\mathrm{pH}$ values (http://www.biolog.com/productsstatic/phenotype_microbial_cells_use.php). All the procedures were carried out by the manufacturer (BiOLOG, Hayward, CA, USA). S. meliloti cells were used to inoculate the wells of the array, which was then incubated at $30^{\circ} \mathrm{C}$ for $72 \mathrm{~h}$ in an OmniLog reader. The metabolic activities of each strain were evaluated in duplicates. Cell respiration rates were monitored colorimetrically over time and are presented as time-course graphs (Bochner et al. 2001). Pairwise comparisons were performed such that $\mathrm{Rm} 1021$ is shown in red and S. meliloti AK21 in green, with the overlapping areas shown in yellow. The 
OmniLog V. 1.5 Comparison Module provided a report consisting of a reproducibility test, the time-course plots and a list of compounds differentiating the metabolism of the test strain, S. meliloti AK21, from that of the reference strain, $\mathrm{Rm} 1021$. The reproducibility report indicated the number of wells for which the difference in the average height (area under the curve divided by the number of measurements) between duplicate runs was less than the threshold value (usually 12 wells).

\section{Additional files}

Additional file 1: List of variable genes derived from CGH studies. The clusters of missing genes are shadowed and identified in the first column (with $p$-value $<0.01$ and $|\log \mathrm{FC}| \geq 2$ ). The gene names and the corresponding $\log _{2}$-fold-change are indicated in the second and third columns. $\mathrm{NCBl}$ and Blast2GO descriptions are shown, together with statistical parameters.

Additional file 2: List of differentially expressed genes obtained by cDNA microarray hybridization. This list includes the raw data for the genes displaying significant differential expression (with $p$-value $<0.05$ ) in Rm1021 versus S. meliloti AK21, both grown in TY medium (1021 vs. AK21). PhoB- and ExpR-regulated genes are indicated, in accordance with the findings of previous studies (Hoang et al. 2004; Krol and Becker 2004; Yuan et al. 2006).

Additional file 3: List of genes identified by SSH. Ordered register of the S. meliloti AK21 contigs obtained by the pyrosequencing of supressed samples. A complete description of the contigs and identities is provided, together with the category classification assigned. Gene identification, if possible, and the top-scoring organism are indicated in columns $D$ and E, respectively. The specificity of the sequence for S. meliloti AK21 is indicated by the list of other organisms displaying identity to the query contig sequence presented in column F. Those found in Rm1021 were not analyzed (-NA-). Columns $\mathrm{H}$ to K include the identity index corresponding to: (1) the Blastn Rm1021 database; (2) the Blastx Rm1021 database; (3) the Blastn NCBI database (nt); and (4) the Blastx NCBI database (nr). Additional Blast2GO descriptions are shown for some of the sequences. A list of the contig profiles identified for Figure 4 is provided. Data updated in May, 2013.

Additional file 4: Phenotypic microarray-derived kinetic studies comparing S. meliloti AK21 with Rm1021. Two-run consensus curves correspond to the pairwise comparison between the test strain S. meliloti AK21 (in green) and the reference strain Rm1021 (in red). Boxed wells exceed the average height threshold in both of the independent experiments. Positive differences correspond to a gain of phenotype or resistance in the test strain with respect to the reference strain. The PM plate used are those with number PM-1 till PM-20 of the Biolog company (http://www.biolog. com/products-static/phenotype_microbial_cells_use.php).

Additional file 5: Comparative genomic analysis, comparing S. meliloti AK21 CGH data with data for other sequenced S. meliloti strains. Circular representation of the three main replicons of S. meliloti: chromosome, chromid pSymB and megaplasmid pSymA. The outer circle shows the genomic position, in Mb, according to the Rm1021 genome annotation. The next four concentric circles represent the missing genes in the analyzed S. meliloti genomes. The number of genomes that have lost the indicated genes is shown from the outer part of the diagram to the inner part, with five genomes in the first circle and 20 genomes in the last circle. Finally, the innermost group of circles indicate the GC skew determined for Rm1021. Highlighted regions in the outer circle correspond to the missing regions described in the main text and detailed in Table 1. The lower $\mathrm{G}+\mathrm{C}$ content of Rm1021 corresponds to the regions missing from most of the $S$. meliloti genomes. The in silico comparison was carried out with BLAST + software and by BBH-based analysis (Camacho et al. 2009; Altenhoff and Dessimoz 2009). We created local protein databases for each genome, updated in May 2013, and established pairwise comparisons with Rm1021: Rm1021 [NCBI:PRJNA57603, PRJNA19]; SM11 [NCBI:PRJNA159685, PRJNA41117]; AK83 [NCBI:PRJNA52607, PRJNA41993]; 2011 [NCBI:PRJNA193772, PRJNA187276]; BL225C [NCBI:PRJNA52605, PRJNA42477]; GR4 [NCBI:PRJNA184823, PRJNA175860]; Rm41 [NCBI:PRJEA176372, PRJEB436]; 1 A42 [NCBI:PRJNA199493, PRJNA167584]; 4H41 [NCBI:PRJNA199075, PRJNA169747]; 5 A14 [NCBI:PRJNA199492, PRJNA167593]; A0641 M [NCBI:PRJNA199490, PRJNA167594]; A0643DD [NCBI:PRJNA199488, PRJNA167595]; AE608H [NCBI:PRJNA199486, PRJNA167596]; AK11 [NCBI:PRJNA199484, PRJNA167597]; AK75 [NCBI:PRJNA199482, PRJNA167598]; C0431A [NCBI:PRJNA199480, PRJNA167599]; C0438LL [NCBI:PRJNA199478, PRJNA167600]; CCNWSX0020 [NCBI:PRJNA180010, PRJNA75085]; and, H1 [NCBI:PRJNA199476, PRJNA167601]. A defined protein was considered to be lost if it met the following criteria: Blastp e-value $\leq 10^{-6}$; Blastp \% identity $\geq 90$; Blastp matched length $\geq 85 \%$ of the annotated gene length.

\section{Authors' contributions}

MDMS carried out the microarray hybridizations and data analysis, participated in the conception and design of the experiments and drafted the manuscript. JALC performed the suppressive subtractive hybridization and bioinformatics analyses, and participated in the conception and design of the study. MFL and NT were responsible for the conception and funding of the study, participated in its design and coordination, and finished the writing of the manuscript. All authors read and approved the final manuscript.

\section{Acknowledgements}

We are grateful to Marco Bazzicalupo for providing the Aral Sea strain used for this study. We also thank Anke Becker's team for useful advice for the microarray experiments and M.J. Soto's team for guidance in mobility assays. The authors also thankfully acknowledge to Gonzalo Claros and the computer resources and technical support provided by the Plataforma Andaluza de Bioinformática of the University of Málaga. Finally, we acknowledge support of the publication fee by the CSIC Open Access Publication Support Initiative through its Unit of Information Resources for Research (URICI). This work was funded by the following grants: PIE 200740i005 from the Spanish CSIC, AGR 252 from Consejería de Innovación, Ciencia y Empresa of Junta de Andalucía, AGL2006-12466/AGR from Comisión Interministerial de Ciencia y Tecnología, and CSD 2009-0006 of the Consolider-Ingenio 2010 program from the Ministerio de Ciencia e Innovación including ERDF (European Regional Development Funds). JALC was awarded a predoctoral fellowship from the JAE-predoctoral program, CSIC

\section{Compliance with ethical guidelines}

Competing interests

The authors declare that they have no competing interests.

Received: 15 January 2015 Accepted: 26 May 2015

Published online: 16 June 2015

\section{References}

Akopyants NS, Fradkov A, Diatchenko L, Hill JE, Siebert PD, Lukyanov SA et al (1998) PCR-based subtractive hybridization and differences in gene content among strains of Helicobacter pylori. Proc Natl Acad Sci USA 95:13108-13113

Altenhoff AM, Dessimoz C (2009) Phylogenetic and functional assessment of orthologs inference projects and methods. PLoS Comput Biol 5:e1000262. doi:10.1371/journal.pcbi.1000262

Bailly X, Olivieri I, Brunel B, Cleyet-Marel JC, Bena G (2007) Horizontal gene transfer and homologous recombination drive the evolution of the nitrogen-fixing symbionts of Medicago species. J Bacteriol 189:5223-5236

Bailly X, Giuntini E, Sexton MC, Lower RPJ, Harrison PW, Kumar N et al (2011) Population genomics of Sinorhizobium medicae based on low-coverage sequencing of sympatric isolates. ISME J 5:1722-1734 
Barloy-Hubler F, Capela D, Barnett MJ, Kalman S, Federspiel NA, Long SR et al (2000) High-resolution physical map of the Sinorhizobium meliloti 1021 pSymA megaplasmid. J Bacteriol 182:1185-1189

Barnett MJ, Fisher RF, Jones T, Komp C, Abola AP, Barloy-Hubler F et al (2001) Nucleotide sequence and predicted functions of the entire Sinorhizobium meliloti pSymA megaplasmid. Proc Natl Acad Sci USA 98:9883-9888

Becker A, Bergès H, Krol E, Bruand C, Rüberg S, Capela D et al (2004) Global changes in gene expression in Sinorhizobium meliloti 1021 under microoxic and symbiotic conditions. Mol Plant Microbe Interact 17:292-303

Biondi EG, Pilli E, Giuntini E, Roumiantseva ML, Andronov EE, Onichtchouk OP et al (2003) Genetic relationship of Sinorhizobium meliloti and Sinorhizobium medicae strains isolated from Caucasian region. FEMS Microbiol Lett 220:207-213

Biondi EG, Tatti E, Comparini D, Giuntini E, Mocali S, Giovannetti L et al (2009) Metabolic capacity of Sinorhizobium (Ensifer) meliloti strains as determined by phenotype microarray analysis. Appl Environ Microbio 75:5396-5404

Bobik C, Meilhoc E, Batut J (2006) FixJ: a major regulator of the oxygen limitation response and late symbiotic functions of Sinorhizobium meliloti. J Bacteriol 188:4890-4902

Bochner BR, Gadzinski P, Panomitros E (2001) Phenotype microarrays for highthroughput phenotypic testing and assay of gene function. Genome Res 11:1246-1255

Bodogai M, Ferenczi S, Bshtovyy D, Miclea P, Papp P, Dusha I (2006) The ntrPR operon of Sinorhizobium meliloti is organized and functions as a toxinantitoxin module. Mol Plant Microbe Interac 19:811-822

Camacho C, Coulouris G, Avagyan V, Ma N, Papadopoulos J, Bealer K et al (2009) BLAST+: architecture and applications. BMC Bioinform 10:421. doi:10.1186/1471-2105-10-421

Carter B, Wu G, Woodward MJ, Anjum MF (2008) A process for analysis of microarray comparative genomics hybridisation studies for bacterial genomes. BMC Genomics 9:53. doi:10.1186/1471-2164-9-53

Chien CT, Maundu J, Cavaness J, Dandurand LM, Orser CS (1992) Characterization of salt-tolerant and salt-sensitive mutants of Rhizobium leguminosarum biovar. viciae strain C12046. FEMS Microbiol Lett 90:135-140

Conesa A, Gotz S, Garcia-Gomez JM, Terol J, Talon M, Robles M (2005) Blast2GO: a universal tool for annotation, visualization and analysis in functional genomics research. Bioinformatics 21:3674-3676

Craig GF, Atkins CA, Bell DT (1991) Effect of salinity on growth of Rhizobium and their infectivity and effectiveness on two species of Acacia. Plant Soil 133:253-262

Crossman LC, Castillo-Ramírez S, McAnnula C, Lozano L, Vernikos GS, Acosta $J$ et al (2008) A common genomic framework for a diverse assembly of plasmids in the symbiotic nitrogen fixing bacteria. PLoS One 3:e2567. doi:10.1371/journal.pone.0002567

Cummings CA, Brinig MM, Lepp PW, van de Pas S, Relman DA (2004) Bordetella species are distinguished by patterns of substantial gene loss and host adaptation. J Bacteriol 186:1484-1492

Diatchenko L, Lau YF, Campbell AP, Chenchik A, Moqadam F, Huang B et al (1996) Suppression subtractive hybridization: a method for generating differentially regulated or tissue-specific cDNA probes and libraries. Proc Natl Acad Sci USA 93:6025-6030

diCenzo G, Milunovic B, Cheng J, Finan TM (2013) The tRNAarg gene and engA are essential genes on the 1.7-Mb pSymB megaplasmid of Sinorhizobium meliloti and were translocated together from the chromosome in an ancestral strain. J Bacteriol 195:202-212

Domínguez-Ferreras A, Pérez-Arnedo R, Becker A, Olivares J, Soto MJ, Sanjuán J (2006) Transcriptome profiling reveals the importance of plasmid pSymB for osmoadaptation of Sinorhizobium meliloti. J Bacteriol 188:7617-7625

Domínguez-Ferreras A, Soto MJ, Pérez-Arnedo R, Olivares J, Sanjuán J (2009) Importance of trehalose biosynthesis for Sinorhizobium meliloti osmotolerance and nodulation of Alfalfa roots. J Bacteriol 191:7490-7499

El-Sheikh EAE, Wood M (1995) Nodulation and $\mathrm{N}_{2}$ fixation by soybean inoculated with salt-tolerant rhizobia or salt-sensitive Bradyrhizobia in saline soil. Soil Biol Biochem 27:657-661

Epstein B, Branca A, Mudge J, Bharti AK, Briskine R, Farmer AD et al (2012) Population genomics of the facultatively mutualistic bacteria Sinorhizobium meliloti and S. medicae. PLoS Genet 8:e1002868

Falgueras J, Lara AJ, Fernandez-Pozo N, Canton FR, Perez-Trabado G, Claros MG (2010) SeqTrim: a high-throughput pipeline for pre-processing any type of sequence read. BMC Bioinform 11:38. doi:10.1186/1471-2105-11-38
Fernandez-Pozo N (2012) Análisis bioinformático del transcriptoma de pino. PhD Thesis, University of Málaga, Spain

Finan TM, Weidner S, Wong K, Buhrmester J, Chain P, Vorhölter FJ et al (2001) The complete sequence of the 1,683-kb pSymB megaplasmid from the $\mathrm{N}_{2}$-fixing endosymbiont Sinorhizobium meliloti. Proc Natl Acad Sci USA 98:9889-9894

Galardini M, Mengoni A, Brilli M, Pini F, Fioravanti A, Lucas S et al (2011) Exploring the symbiotic pangenome of the nitrogenfixing bacterium Sinorhizobium meliloti. BMC Genomics 12:235. doi:10.1186/1471-2164-12-235

Galardini M, Bazzicalupo M, Biondi E, Brambilla E, Brilli M, Bruce D et al (2013a) Permanent draft genome sequences of the symbiotic nitrogen fixing Ensifer meliloti strains BO21CC and AK58. Stand Genomic Sci 9:325-333. doi:10.4056/sigs.3797438

Galardini M, Pini F, Bazzicalupo M, Biondi EG, Mengoni A (2013b) Replicondependent bacterial genome evolution: the case of Sinorhizobium meliloti. Genome Biol Evol 5:542-558

Galardini M, Mengoni A, Biondi EG, Semeraro R, Florio A, Bazzicalupo M et al (2014) DuctApe: a suite for the analysis and correlation of genomic and OmniLog ${ }^{\text {TM }}$ phenotype microarray data. Genomics 103:1-10

Galbraith E, Antonopoulos D, White B (2004) Suppressive subtractive hybridization as a tool for identifying genetic diversity in an environmental metagenome: the rumen as a model. Environ Microbiol 6:928-937

Galibert F, Finan TM, Long SR, Pühler A, Abola P, Ampe F et al (2001) The composite genome of the legume symbiont Sinorhizobium meliloti. Science 293:668-672

Giuntini E, Mengoni A, De Filippo C, Cavalieri D, Aubin-Horth N, Landry CR et al (2005) Large-scale genetic variation of the symbiosisrequired megaplasmid pSymA revealed by comparative genomic analysis of Sinorhizobium meliloti natural strains. BMC Genomics 6:158. doi:10.1186/1471-2164-6-158

Guinane CM, Fitzgerald JR (2008) Microarray comparative genomic hybridization for the analysis of bacterial population genetics and evolution. Methods Mol Biol 431:47-54

Guo H, Sun S, Finan TM, Xu J (2005) Novel DNA sequences from natural strains of the nitrogen-fixing symbiotic bacterium Sinorhizobium meliloti. Appl Environ Microbiol 71:7130-7138

Guo H, Sun S, Eardly B, Finan T, Xu JP (2009) Genome variation in the symbiotic nitrogen-fixing bacterium Sinorhizobium meliloti. Genome 52:862-875

Gurskaya NG, Diatchenko L, Chenchik A, Siebert PD, Khaspekov GL, Lukyanov KA et al (1996) Equalizing cDNA subtraction based on selective suppression of polymerase chain reaction: cloning of Jurkat cell transcripts induced by phytohemaglutinin and phorbol 12-myristate 13-acetate. Anal Biochem 240:90-97

Han Y, Zhou D, Pang X, Zhang L, Song Y, Tong Z et al (2005) Comparative transcriptome analysis of Yersinia pestis in response to hyperosmotic and high-salinity stress. Res Microbiol 156:403-415

Hashem FM, Swelim DM, Kuykendall LD, Mohamed Al, Abdel-Wahab SM, Hegazi NI (1998) Identification and characterization of salt- and thermo-tolerant Leucaena-nodulating Rhizobium strains. Biol Fertil Soils 27:335-341

Hellriegel $H$, Wilfarth $H$ (1888) Untersuchungen uber die Stickstoffnahrung der Gramineen und Leguminosen. Beilageheft zu der Zeitschrift des Vereins fur Rubenzucker-Industrie Deutschen Reichs, p 234

Hermans APHM, Abee T, Zwietering MH, Aarts HJM (2005) Identification of novel Salmonella enterica serovar Typhimurium DT104-specific prophage and nonprophage chromosomal sequences among serovar Typhimurium isolates by genomic subtractive hybridization. Appl Environ Microbiol 71:4979-4985

Hoang HH, Becker A, González JE (2004) The LuxR homolog ExpR, in combination with the Sin quorum sensing system, plays a central role in Sinorhizobium meliloti gene expression. J Bacteriol 186:5460-5472

Hoang HH, Gurich N, González JE (2008) Regulation of motility by the ExpR/Sin quorum-sensing system in Sinorhizobium meliloti. J Bacteriol 190:661-671

Huang X, Madan A (1999) CAP3: a DNA sequence assembly program. Genome Res 9:868-877

Ibragimova MV, Rumyantseva ML, Onishchuk OP, Belova VS, Kurchak ON, Andronov EE et al (2006) Symbiosis between the root-nodule bacterium Sinorhizobium meliloti and alfalfa (Medicago sativa) under salinization conditions. Mikrobiologiya 75:94-100 
Jebara M, Mhamdi R, Aouani ME, Ghrir R, Mars M (2001) Genetic diversity of Sinorhizobium populations recovered from different Medicago varieties cultivated in Tunisian soils. Can J Microbiol 47:139-147

Jones KM, Kobayashi H, Davies BW, Taga ME, Walker GC (2007) How rhizobial symbionts invade plants: the Sinorhizobium-Medicago model. Nat Rev Microbiol 5:619-633

Kanesaki Y, Suzuki I, Allakhverdiev SI, Mikami K, Murata N (2002) Salt stress and hyperosmotic stress regulate the expression of different sets of genes in Synechocystis sp. PCC 6803. Biochem Biophys Res Commun 290:339-348

Krol E, Becker A (2004) Global transcriptional analysis of the phosphate starvation response in Sinorhizobium meliloti strains 1021 and 2011. Mol Genet Genomics 272:1-17

Lal B, Khanna S (1995) Selection of salt-tolerant Rhizobium isolates of Acacia nilotica. World J Microbiol Biotechnol 10:637-639

Lukyanov SA, Gurskaia NG, Lukyanov KA, Tarabykin VS, Sverdlov ED (1994) Highly-effective subtractive hybridization of cDNA. Bioorg Khim 20:701-704

Ma W, Charles TC, Glick BR (2004) Expression of an exogenous 1-aminocyclopropane-1-carboxylate deaminase gene in Sinorhizobium meliloti increases its ability to nodulate alfalfa. Appl Environ Microbiol 70:5891-5897

Malloff CA, Fernandez RC, Lam WL (2001) Bacterial comparative genomic hybridization: a method for directly identifying lateral gene transfer. J Mol Biol 312:1-5

Martínez-Abarca F, Martínez-Rodríguez L, López-Contreras JA, Jiménez-Zurdo J, Toro N (2013) Complete genome sequence of the alfalfa symbiont Sinorhizobium/Ensifer meliloti strain GR4. Genome Announc 1:e0017412. doi:10.1128/genomeA.00174-12

Mashhady AS, Salem SH, Barakh FN, Heggo AM (1998) Effect of salinity on survival and symbiotic performance between Rhizobium meliloti and Medicago sativa in Saudi Arabian soils. Arid Soil Res Rehabil 12:3-14

Mavingui P, Flores M, Guo X, Dávila G, Perret X, Broughton WJ et al (2002) Dynamics of genome architecture in Rhizobium sp. strain NGR234. J Bacteriol 184:171-176

Meade HM, Signer ER (1977) Genetic mapping of Rhizobium meliloti. Proc Natl Acad Sci USA 74:2076-2078

Mercado-Blanco J, Toro N (1996) Plasmids in rhizobia: the role of nonsymbiotic plasmids. Mol Plant Microbe Interact 19:535-545

Moawad H, Beck D (1991) Some characteristics of Rhizobium leguminosarum isolates from uninoculated field-grown lentil. Soil Biol Biochem 23:917-925

Mohammad RM, Akhavan-Kharazian M, Campbell WF, Rumbaugh MD (1991) Identification of salt and drought-tolerant Rhizobium meliloti L. strains. Plant Soil 134:271-276

Murray AE, Lies D, Li G, Nealson K, Zhou J, Tiedje JM (2001) DNA/DNA hybridization to microarrays reveals gene-specific differences between closely related microbial genomes. Proc Natl Acad Sci USA 98:9853-9858

Nogales J, Campos R, BenAbdelkhalek H, Olivares J, Lluch C, Sanjuan J (2002) Rhizobium tropici genes involved in free-living salt tolerance are required for the establishment of efficient nitrogen-fixing symbiosis with Phaseolus vulgaris. Mol Plant Microbe Interact 15:225-232

Nogales J, Domínguez-Ferreras A, Amaya-Gómez CV, van Dillewijn P, Cuéllar V, Sanjuán J et al (2010) Transcriptome profiling of a Sinorhizobium meliloti fadD mutant reveals the role of rhizobactin 1021 biosynthesis and regulation genes in the control of swarming. BMC Genomics 11:157. doi:10.1186/1471-2164-11-157

Nogales J, Bernabéu-Roda L, Cuéllar V, Soto MJ (2012) ExpR is not required for swarming but promotes sliding in Sinorhizobium meliloti. J Bacteriol 194:2027-2035

Ohwada T, Sasaki Y, Koike H, Igawa K, Sato T (1998) Correlation between NaCl sensitivity of Rhizobium bacteria and ineffective nodulation of leguminous plants. Biosci Biotechnol Biochem 62:2086-2090

Paffetti D, Scotti C, Gnocchi S, Fancelli S, Bazzicalupo M (1996) Genetic diversity of an Italian Rhizobium meliloti population from different Medicago sativa varieties. Appl Environ Microbiol 62:2279-2285

Pellock BJ, Teplitski M, Boinay RP, Bauer WD, Walker GC (2002) A LuxR homolog controls production of symbiotically active extracellular polysaccharide II by Sinorhizobium meliloti. J Bacteriol 184:5067-5076

Peoples MB, Ladha JK, Herridge DF (1995) Enhancing legume $\mathrm{N}_{2}$ fixation through plant and soil management. Plant Soil 174:83-101
Peters A, Kulajta C, Pawlik G, Daldal F, Koch HG (2008) Stability of the cbb3-type cytochrome oxidase requires specific CcoQ-CcoP interactions. J Bacteriol 190:5576-5586

Rajashekara G, Glasner JD, Glover DA, Splitter GA (2004) Comparative wholegenome hybridization reveals genomic islands in Brucella species. J Bacteriol 186:5040-5051

Roumiantseva ML, Andronov EE, Sharypova LA, Dammann-Kalinowski T, Keller M, Young JP et al (2002) Diversity of Sinorhizobium meliloti from the Central Asian alfalfa gene center. Appl Environ Microbiol 68:4694-4697

Ruan X, Peters NK (1992) Isolation and characterization of rhizobitoxine mutants of Bradyrhizobium japonicum. J Bacteriol 174:3467-3473

Ruan X, Zhang C, Peters NK (1993) Bradyrhizobium japonicum rhizobitoxine genes and putative enzyme functions: expression requires a translational frameshift. Proc Natl Acad Sci USA 90:2641-2645

Rüberg S, Tian ZX, Krol E, Linke B, Meyer F, Wang Y et al (2003) Construction and validation of a Sinorhizobium meliloti whole genome DNA microarray: genome-wide profiling of osmoadaptive gene expression. J Biotechnol 106:255-268

Salama N, Guillemin K, McDaniel TK, Sherlock G, Tompkins L, Falkow S (2000) A whole-genome microarray reveals genetic diversity among Helicobacter pylori strains. Proc Natl Acad Sci USA 97:14668-14673

Schneiker-Bekel S, Wibberg D, Bekel T, Blom J, Linke B, Neuweger H et al (2011) The complete genome sequence of the dominant Sinorhizobium meliloti field isolate SM11 extends the S. meliloti pan-genome. J Biotech 155:20-33

Sharma RS, Mishra V, Mohmmed A, Babu CR (2008) Phage specificity and lipopolysaccharides of stem- and root-nodulating bacteria (Azorhizobium caulinodans, Sinorhizobium spp., and Rhizobium spp.) of Sesbania spp. Arch Microbiol 189:411-418

Soto MJ, Fernández-Pascual M, Sanjuán J, Olivares J (2002) A fadD mutant of Sinorhizobium meliloti shows multicellular swarming migration and is impaired in nodulation efficiency on alfalfa roots. Mol Microbiol 43:371-382

Souza V, Nguyen TT, Hudson RR, Pinero D, Lenski RE (1992) Hierarchical analysis of linkage disequilibrium in Rhizobium populations: evidence for sex? Proc Natl Acad Sci USA 89:8389-8393

Stiens M, Schneiker S, Keller M, Kuhn S, Pühler A, Schlüter A (2006) Sequence analysis of the 144-kilobase accessory plasmid pSmeSM11a, isolated from a dominant Sinorhizobium meliloti strain identified during a long-term field release experiment. Appl Environ Microbiol 72(5):3662-3672

Stiens M, Becker A, Bekel T, Gödde V, Goesmann A, Niehaus K et al (2008) Comparative genomic hybridisation and ultrafast pyrosequencing revealed remarkable differences between the Sinorhizobium meliloti genomes of the model strain Rm1021 and the field isolate SM11. J Biotech 136:31-37

Sugawara M, Okazaki S, Nukui N, Ezura H, Mitsui H, Minamisawa K (2006) Rhizobitoxine modulates plant-microbe interactions by ethylene inhibition. Biotechnol Adv 24:382-388

Sugawara M, Epstein B, Badgley BD, Unno T, Xu L, Reese J et al (2013) Comparative genomics of the core and accessory genomes of 48 Sinorhizobium strains comprising five genospecies. Genome Biol 14(2):R17. doi:10.1186/ gb-2013-14-2-r17

Sullivan JT, Ronson CW (1998) Evolution of rhizobia by acquisition of a 500-kb symbiosis island that integrates into a phe-tRNA gene. Proc Natl Acad Sci USA 95:5145-5149

Taboada EN, Luebbert CC, Nash JH (2007) Studying bacterial genome dynamics using microarray-based comparative genomic hybridization. Methods Mol Biol 396:223-253

Tian CF, Zhou YJ, Zhang YM, Li QQ, Zhang YZ, Li DF et al (2012) Comparative genomics of rhizobia nodulating soybean suggests extensive recruitment of lineage-specific genes in adaptations. Proc Natl Acad Sci USA 109:8629-8634

Torres MJ, Hidalgo-García A, Bedmar EJ, Delgado MJ (2013) Functional analysis of the copy 1 of the fixNOQP operon of Ensifer meliloti under free-living micro-oxic and symbiotic conditions. J Appl Microbiol 114:1772-1781

Wei W, Jiang J, Li W, Wang L, Yang SS (2004) Isolation of salt-sensitive mutants from Sinorhizobium meliloti and characterization of genes involved in salt tolerance. Lett Appl Microbiol 39:278-283

Wu L, Liu X, Fields MW, Thompson DK, Bagwell CE, Tiedje JM et al (2008) Microarray-based whole-genome hybridization as a tool for determining prokaryotic species relatedness. ISME J 2:642-655 
Young JPW, Crossman LC, Johnston AWB, Thomson NR, Ghazoui ZF, Hull KH et al (2006) The genome of Rhizobium leguminosarum has recognizable core and accessory components. Genome Biol 7:R34. doi:10.1186/ gb-2006-7-4-r34

Yuan ZC, Zaheer R, Morton R, Finan TM (2006) Genome prediction of PhoB regulated promoters in Sinorhizobium meliloti and twelve proteobacteria. Nucl Acids Res 34:2686-2697

Yuhashi K, Ichikawa N, Ezura H, Akao S, Minakawa Y, Nukui N et al (2000) Rhizobitoxine production by Bradyrhizobium elkanii enhances nodulation and competitiveness on Macroptilium atropurpureum. Appl Environ Microbiol 66:2658-2663
Zahran HH (1991) Conditions for successful Rhizobium-legume symbiosis in saline environments. Biol Fertil Soils 12:73-80

Zahran HH (1999) Rhizobium-legume symbiosis and nitrogen fixation under severe conditions and in an arid climate. Microbiol Mol Biol Rev 63:968-989

Zhang Q, Melcher U, Zhou L, Najar FZ, Roe BA, Fletcher J (2005) Genomic comparison of plant pathogenic and nonpathogenic Serratia marcescens strains by suppressive subtractive hybridization. Appl Environ Microbiol 71:7716-7723

Zou N, Dort PJ, Marcar NE (1995) Interaction of salinity and rhizobial strains on growth and $\mathrm{N}_{2}$ fixation by Acacia ampliceps. Soil Biol Biochem 27:409-413

\section{Submit your manuscript to a SpringerOpen ${ }^{\odot}$ journal and benefit from:}

- Convenient online submission

- Rigorous peer review

- Immediate publication on acceptance

- Open access: articles freely available online

- High visibility within the field

- Retaining the copyright to your article

Submit your next manuscript at $>$ springeropen.com 